\title{
ABSTRAK \\ GAMBARAN TINGKAT KEPATUHAN PASIEN TB PARU DALAM PENGOBATAN TB PARU DI PUSKESMAS KOTA ATAMBUA
}

\author{
Emilia Hoar Taek. ${ }^{1}$ \\ Maria Fatimah W. A. Fouk, S.Kep.,Ns.,M.Kep. ${ }^{2}$ \\ Melkianus Ratu, SKM.,MHID. ${ }^{3}$
}

12 : Program Studi Keperawatan Fakultas Pertanian Universitas Timor Kampus Atambua. Jln.Wehor Desa Kabuna Kecamatan Kakuluk Mesak Belu NTT, 85711

Kepatuhan pasien dalam menjalankan pengobatan merupakan salah satu faktor yang menentukan dalam keberhasilan terapi, namun kepatuhan untuk melakukan pengobatan oleh pasien seringkali rendah termasuk pada pengobatan tuberculosis. Penelitian ini bertujuan untuk mengetahui gambaran tingkat kepatuhan pasien TB paru dalam pangobatan TB paru di Puskesmas Kota Atambua. Pengambilan data melalui wawancara langsung menggunakan kuisioner dengan pendekatan kuantitatif metode deskriptif. Sampel adalah Pasien TB Paru yang didiagnosa dan sedang menjalani pengobatan TB paru pada bulan Januari - Juni 2018 di Puskesmas Kota Atambua. Berdasarkan hasil analisis univariat didapatkan bahwa dari 22 responden di Puskesmas Kota Atambua 90.9\% patuh terhadap pengobatan TB paru.

Kata kunci: gambaran tingkat kepatuhan pasien, tuberculosis

\section{ABSTRACT \\ OVERVIEW OF COMPLIANCE LEVEL OF PATIENTS WITH PULMONARY TB IN THE TREATMENT OF PULMONARY TB IN ATAMBUA CITY HEALTH CENTER}

\author{
Emilia Hoar Taek. ${ }^{1}$ \\ Maria Fatimah W. A. Fouk, S.Kep., Ns., M.Kep. ${ }^{2}$ \\ Melkianus Ratu, SKM., MHID. ${ }^{3}$
}

12 3: Nursing Study Program, Faculty Of Agriculture, University Of Timor,Atambua Campus. Jln.Wehor Desa Kabuna Kecamatan Kakuluk Mesak Belu NTT, 85711

Patient compliance in carrying out treatment is one of the decisive factors in the success of therapy, but adherence to treatment by patients is often low including tuberculosis treatment.This study aims to describe the level of compliance of pulmonary TB patients in the treatment of pulmonary TB in Atambua City Health Center.Retrieving data through interviews directly using questionnaires with quantitative methods descriptive approach.The sample was pulmonary TB patients who were diagnosed and were undergoing pulmonary tuberculosis treatment in January - June 2018 at the Atambua City Health Center.Based on the results of univariate analysis, it was found that out of 22 respondents in the Atambua City Health Center $90.9 \%$ adhered to the treatment of pulmonary TB.

Keywords: description of level of patient compliance, tuberculosis 


\section{PENDAHULUAN}

Tuberkulosis paru adalah suatu penyakit menular yang paling sering mengenai parenkim paru, biasanya disebabkan oleh Mycobacterium tuberculosis. (Brunner \& Suddarth, 2013). Gejala utama adalah batuk selama 2 minggu atau lebih, batuk disertai dengan gejala tambahan yaitu dahak, dahak bercampur darah, sesak nafas, badan lemas, nafsu makan menurun, berat badan menurun, malaise, berkeringat malam hari tanpa kegiatan fisik, demam lebih dari 1 bulan (Riskesdas, 2013). TB paru merupakan penyakit infeksi yang menular yang membutuhkan upaya pengobatan yang lama. Dengan demikian tingkat kepatuhan minum obat TB Paru sangatlah penting, karena bila pengobatan tidak dilakukan secara teratur dan tidak sesuai dengan waktu yang telah di tentukan maka akan dapat timbul kekebalan (resistance) kuman tubeculosis terhadap Obat Anti Tuberculosis (OAT) secara meluas atau disebut dengan Multi Drug Resistance (MDR). (Kirana, Lutfiyati, Wahyu, 2015).

Menurut Depkes RI (2008) dijelaskan bahwa kepatuhan rata-rata pasien pada pengobatan jangka panjang terhadap penyakit kronis di negara maju hanya sebesar $50 \%$ sedangkan di negara berkembang jumlah tersebut bahkan lebih rendah. Ketidakpatuhan pasien dalam pengobatan merupakan masalah kesehatan yang serius dan sering terjadi pada pasien dengan penyakit kronis, seperti pada penyakit tuberkulosis paru. Banyak faktor yang berhubungan dengan kepatuhan terhadap terapi TB paru, termasuk karakteristik pasien, hubungan antara petugas pelayanan kesehatan dan pasien, regimen terapi dan sistem penyelenggara pelayanan kesehatan. Sedangkan kepatuhan (Compliance atau Adherence) menjelaskan sejauh mana pasien mengikuti instruksi-instruksi atau saran medis. Selain itu terkait dengan terapi obat, kepatuhan pasien juga didefinisikan sebagai derajat kesesuaian antara riwayat dosis yang sebenarnya dengan regimen dosis obat yang diresepkan. Oleh karena itu, pengukuran kepatuhan pada dasarnya mempresentasikan perbandingan antara dua rangkaian kejadian, yaitu bagaimana nyatanya obat diminum dengan bagaimana obat seharusnya diminum sesuai resep. (Pameswari, Halim, Yustika, 2016)

Berdasarkan Global Tuberculosis Report (2015) yang dirilis oleh WHO, sebanyak 58\% kasus TB Paru baru terjadi di Asia Tenggara dan wilayah Western Pacific pada tahun 2014. India, Indonesia dan Tiongkok menjadi negara dengan jumlah kasus TB terbanyak di dunia, masing-masing 23\%, $10 \%$ dan $10 \%$ dari total kejadian di seluruh dunia. Indonesia menempati peringkat kedua bersama Tiongkok. Satu juta kasus baru pertahun diperkirakan terjadi di Indonesia (Irianti at all, 2016). Sedangkan menurut Global Tuberculosis Control WHO Report (2007), Indonesia berada di peringkat ke tiga jumlah kasus tuberkulosis terbesar di dunia (528.000 kasus) setelah India dan China. Data yang diperolah dari profil kesehatan propinsi Nusa tenggara timur tahun 2015 bahwa angka kasus TB Paru seluruhnya (case netification rate) sebanyak 4.789 kasus (93,53 per 100.000 penduduk) berarti pada tahun 2015 dalam setiap 100.000 penduduk terdapat penderita TB Paru (untuk semua tipe) sebanyak 93 orang dimana kasus tertinggi adalah laki-laki dan Kabupaten Belu menduduki urutan kedua kasus terbanyak dengan jumlah 560 orang yang terbagi di seluruh fasilitas kesehatan. Data terbaru yang diperoleh dari Dinas Kesehatan Kabupaten Belu dari bulan Januari sampai 30 September 2018, jumlah pasien TB Paru terbanyak berada pada Puskesmas Kota Atambua dengan jumlah 48 orang. 
Ketidakpatuhan terhadap pengobatan akan mengakibatkan tingginya angka kegagalan pengobatan penderita TB paru, dapat meningkatkan resiko kesakitan, kematian dan menyebabkan semakin banyak ditemukan penderita TB paru dengan Basil Tahan Asam (BTA) yang resisten terhadap Obat Anti Tuberculosis (OAT) secara meluas atau disebut dengan Multi Drug Resistance (MDR). Pasien yang resisten tersebut akan menjadi sumber penularan kuman yang resisten di masyarakat. Hal ini tentunya akan mempersulit pemberantasan penyakit TB paru di Indonesia serta memperberat beban pemerintah (Kirana, Lutfiyati, Wahyu, 2015).

Mengingat TB Paru merupakan penyakit yang menular sehingga kepatuhan pengobatan TB Paru merupakan hal yang penting untuk di analisis karena berdasarkan hasil analisis terhadap 35 total responden yang dilakukan oleh peneliti terdahulu (Kirana,Lutfiyati, Wahyu, 2015), Menjelaskan bahwa terdapat 22 (63\%) responden yang patuh dan 13 responden (37\%) yang tidak patuh dalam menjalankan pengobatan tuberkulosis pada bulan Februari sampai dengan Maret 2015 di BKPM Magelang dengan alasan ketidakpatuhan adalah karena kesibukan sehingga lupa meminum obat dan telat memeriksa ulang dahak. Hal yang sama juga ditemukan di Puskesmas Kota Atambua dimana berdasarkan hasil wawancara dengan pengelola program TB Paru di Puskesmas Kota Atambua dijelaskan bahwa penderita TB paru yang tercatat selama tahun 2015 adalah sebanyak 45 orang, terdiri dari 33 orang laki-laki dan 12 orang perempuan, pada tahun 2016 penderita TB paru sebanyak 16 orang laki-laki dan 13 orang perempuan, pada tahun 2017 penderita TB paru meningkat menjadi 53 orang yang terdiri dari laki-laki 28 orang dan perempuan 25 orang. Selain itu juga dijelaskan bahwa belum ada penelitian sebelumnya tentang gambaran tingkat kepatuhan pemakaian obat oleh pasien TB Paru di Puskesmas Kota Atambua. Oleh karena itu peneliti tertarik untuk melakukan penelitian tentang gambaran tingkat kepatuhan pasien TB Paru dalam pengobatan TB Paru di Puskesmas Kota Atambua.

\section{METODOLOGI}

Penelitian ini merupakan penelitian deskriptif kuantitatif dengan pendekatan cross sectional untuk mengetahui tingkat kepatuhan pasien TB Paru dalam pengobatan TB Paru di Puskesmas Kota Atambua. Populasinya adalah pasien TB Paru yang telah selesai menjalani pengobatan paket di Puskesmas Kota Atambua. Pengambilan sampel menggunakan accidental sampling. Terhadap 22 orang responden yang memenuhi kriteria inklusi, yaitu bersedia menjadi responden; pasien TB Paru yang yang telah selesai menjalani pengobatan TB Paru; pasien TB Paru yang didiagnosa dan sedang menjalani pengobatan TB paru pada bulan Januari - Juni 2018 di Puskesmas Kota Atambua; dan kasus baru tanpa komplikasi. Sedangkan kriteria eksklusinya adalah: pasien relaps; pasien TB Paru yang dengan penyakit penyerta; pasien TB Paru yang sedang menjalani pengobatan di Puskesmas Kota Atambua. Peneliti menggunakan kuisioner untuk evaluasi responden dalam minum obat. Data dianalisa menggunakan univariat untuk mengidentifikasi tingkat kepatuhan pasien dalam minum obat TB Paru.

\section{HASIL PENELITIAN}

\section{a. Gambaran Umum Tempat Penelitian \\ UPTD Puskesmas Kota Atambua berdiri pada tahun 1991 di Kelurahan}


Beirafu, Kecamatan Atambua Barat, Kabupaten Belu, dengan cakupan wilayah kerjanya mencakup 12 Kelurahan. Selanjutnya dalam perjalanan dilakukan penambahan sarana penunjang pelayanan beberapa puskesmas pembantu yakni Fatubenao, Lolowa, Umanen dan Berkase. Seiring berdirinya Puskesmas Haliwen maka wilayah kerja UPTD Puskesmas Kota Atambua (Kelurahan Manumutin) dialihkan ke Puskesmas Haliwen dan Puskesmas Kota mendapat tambahan Desa Tukuneno (Kecamatan Tasifeto Barat). Pada bulan Februari 2011 berdiri Puskesmas Umanen yang mencakup 4 Kelurahan (Beirafu, Bardao,Tulamalae, Umanen). Tahun 2012 berdiri Puskesmas Atambua Selatan ang mencakup 4 Kelurahan dan 1 Desa (Manuaman, Lidak, Rinbesi, Fatukbot dan Tukuneno). Pada tanggal 11 Mei 2015 UPTD Puskesmas Kota Atambua pindah kekompleks Kantor Camat Kota Atambua, Kelurahan Tenukiik, Jalan Adi Sucipto Nomor 38 B dan memiliki wilayah kerja 3 Kelurahan, yaitu Kelurahan Atambua, Kelurahan Tenukiik dan Kelurahan Fatubenao.

UPTD Puskesmas Kota Atambua merupakan Puskesmas Rawat Jalan, terletak di Kelurahan Tenukiik, Kecamatan Kota Atambua, Kabupaten Belu, Provinsi Nusa Tenggara Timur, dengan luas tanah sebesar 20 x $30 \mathrm{~m} 2$. Jarak dari Puskesmas ke Ibu Kota Kabupaten $\pm 2 \mathrm{~km}$; jarak dengan Ibu Kota Provinsi $\pm 281 \mathrm{~km}$. Batas - batas wilayah kerja UPTD Puskesmas Kota Atambua sebagai berikut: Sebelah Utara berbatasan dengan Kelurahan Manumutin, Sebelah Selatan berbatasan dengan Kelurahan Rinbesi, Sebelah Timur berbatasan dengan Desa Umaklaran, Sebelah Barat berbatasan dengan Kelurahan Tulamalae.

Wilayah Kerja UPTD Puskesmas Kota Atambua tersebar dalam 3 Kelurahan yaitu : Kelurahan Atambua, Kelurahan
Fatubenao, dan Kelurahan Tenukiik dengan wilayah kerjanya sebesar 13,55 $\mathrm{km} 2$ dan jumlah penduduknya di tahun 2018 sebesar 18.585 jiwa dari $4.248 \mathrm{KK}$.

\section{b. Hasil Penelitian}

Tabel 1

Distribusi Frekuensi Responden Bedasarkan Jenis Kelamin Di Puskesmas Kota Atambua Bulan Januari- Februari $2019(n=22)$

\begin{tabular}{ccc}
\hline $\begin{array}{c}\text { Jenis } \\
\text { Kelamin }\end{array}$ & Frekuensi & $\begin{array}{c}\text { Persentase } \\
(\mathbf{\%})\end{array}$ \\
\hline Laki-Laki & 11 & 50.0 \\
Perempuan & 11 & 50.0 \\
\hline Total & $\mathbf{2 2}$ & $\mathbf{1 0 0}$ \\
\hline Sumber : Data Pimer 2019 &
\end{tabular}

Berdasarkan Tabel 1 diketahui bahwa setengah dari responden adalah berjenis kelamin laki-laki yaitu 11 orang $(50.0 \%)$ dan setengahnya berjenis kelamin perempuan yaitu sebesar 11 orang $(50.0 \%)$.

Tabel 2

Distribusi Frekuensi Responden

Bedasarkan Umur Di Puskesmas Kota Atambua Bulan Januari - Februari 2019 $(n=22)$

\begin{tabular}{|c|c|c|}
\hline Umur & Frekuensi & $\begin{array}{c}\text { Persentase } \\
(\%)\end{array}$ \\
\hline 15-24 Tahun & 5 & 22.7 \\
\hline 25-34 Tahun & 3 & 13.6 \\
\hline 35-44Tahun & 4 & 18.2 \\
\hline 45-54 Tahun & 2 & 9.1 \\
\hline$\geq 55$ Tahun & 8 & 36.4 \\
\hline Total & 22 & 100 \\
\hline
\end{tabular}

Berdasarkan tabel 2 diketahui bahwa hampir setengah dari responden berusia $\geq$ 55 tahun yakni sebanyak 8 orang $(36.4 \%)$. 
Dan sebagian kecil responden berusia 4554 Tahun yakni sebanyak 2 orang $(9.1 \%)$.

Tabel 3

Distribusi Frekuensi Responden

Berdasarkan Tingkat Pendidikan Di

Puskesmas Kota Atambua Bulan Januari Februari $2019(n=22)$

\begin{tabular}{ccc}
\hline $\begin{array}{c}\text { Tingkat } \\
\text { Pendidikan }\end{array}$ & Frekuensi & $\begin{array}{c}\text { Persentase } \\
(\%)\end{array}$ \\
\hline Tidak & 4 & 18.2 \\
Sekolah & & \\
SD & 3 & 13.6 \\
SMP & 3 & 13.6 \\
SMA & 10 & 45.5 \\
Diploma / & 2 & 9.1 \\
Sarjana & & \\
\hline Total & $\mathbf{2 2}$ & $\mathbf{1 0 0}$ \\
\hline
\end{tabular}

Sumber : Data Primer 2019

Berdasarkan tabel 3 diketahui bahwa hamper setengah dari responden adalah berpendidikan SMA dengan jumlah sebanyak 10 orang (45.5\%), dan paling kecil presentasinya adalah berpendidikan Diploma/Sarjana yaitu sebanyak 2 orang $(9.1 \%)$.

Tabel 4

Distribusi Frekuensi Responden

Berdasarkan Pekerjaan Di Puskesmas

Kota Atambua Bulan Januari- Februari $2019(n=22)$

\begin{tabular}{ccc}
\hline Pekerjaan & $\begin{array}{c}\text { Fre } \\
\text { kue } \\
\text { nsi }\end{array}$ & $\begin{array}{c}\text { Persentase } \\
(\mathbf{\%})\end{array}$ \\
\hline Tidak Kerja & 1 & 4.5 \\
Pelajar / Mahasiswa & 3 & 13.6 \\
Pegawai & 2 & 9.1 \\
Wirausaha / Pedagang & 3 & 13.6 \\
IRT & 6 & 27.3 \\
Lain - lain & 7 & 31.8 \\
\hline Total & $\mathbf{2 2}$ & $\mathbf{1 0 0}$
\end{tabular}

Sumber : Data Primer 2019

Berdasarkan table 4 diketahui bahwa hampir setengah dari responden mempunyai pekerjaan pada kelompok lain-lain sebanyak 7 orang $(31.8 \%)$, dan paling sedikit presentasinya adalah tidak kerja sebanyak 1 orang (4.5\%). Adapun lain-lain dimaksud adalah pensiunan PNS, pensiunan TNI, Petani, Buruh, dan pekerjaan lain yang tidak tentu.

\section{Tabel 5}

Distribusi Frekuensi Responden Berdasarkan Pendapatan Keluarga Di Puskesmas Kota Atambua Bulan Januari Februari $2019(\mathrm{n}=22)$

\begin{tabular}{ccc}
\hline Pendapatan & $\begin{array}{c}\text { Frek } \\
\text { uensi }\end{array}$ & $\begin{array}{c}\text { Presentase } \\
(\mathbf{\%})\end{array}$ \\
\hline $\begin{array}{c}\text { Kurang dari 1 juta } \\
\text { 1 juta s.d kurang dari } 2 \\
\text { juta }\end{array}$ & 6 & 27.3 \\
$\begin{array}{c}\text { 2 juta s.d kurang dari } 4 \\
\text { juta }\end{array}$ & 4 & 54.5 \\
\hline Total & $\mathbf{2 2}$ & $\mathbf{1 0 0}$ \\
\hline Sumber : Data Primer 2019 & &
\end{tabular}

Dari tabel 5 diatas diketahui bahwa sebagian besar responden mempunyai pendapatan keluarga perbulan 1 juta s.d kurang dari 2 juta yaitu sebanyak 12 orang (54.5\%), dan sebagian kecil responden mempunyai pendapatan keluarga 2 juta s.d kurang dari 4 juta sebanyak 4 orang $(18.2 \%)$.

\section{Tabel 4.6}

Distribusi Frekuensi Responden

Berdasarkan Lama Berobat Di Puskesmas Kota Atambua Bulan Januari - Februari

\begin{tabular}{ccc}
\multicolumn{3}{c}{$2019(\mathrm{n}=22)$} \\
\hline $\begin{array}{c}\text { Lama } \\
\text { Berobat }\end{array}$ & Frekuensi & $\begin{array}{c}\text { Presentase } \\
(\boldsymbol{\%})\end{array}$ \\
\hline 6 bulan & 22 & 100 \\
\hline Total & $\mathbf{2 2}$ & $\mathbf{1 0 0}$ \\
\hline
\end{tabular}

Sumber : Data Primer 2019

Berdasarkan tabel 6 diketahui bahwa seluruh responden dalam penelitian ini yaitu sebanyak 22 orang (100\%), membutuhkan waktu 6 bulan untuk berobat. 
Tabel 7

Distribusi Frekuensi Responden

Berdasarkan Status Kepatuhan Di

Puskesmas Kota Atambua Bulan Januari -

Februari $2019(n=22)$

\begin{tabular}{ccc}
\hline $\begin{array}{c}\text { Status } \\
\text { Kepatuhan }\end{array}$ & Frekuensi & $\begin{array}{c}\text { Presentase } \\
(\boldsymbol{\%})\end{array}$ \\
\hline $\begin{array}{c}\text { Patuh } \\
\text { Tidak }\end{array}$ & 20 & 90.91 \\
Patuh & 2 & 9.09 \\
\hline Total & $\mathbf{2 2}$ & $\mathbf{1 0 0}$ \\
\hline Sumber : Data Primer 2019 &
\end{tabular}

Berdasarkan tabel 7 didapatkan sebagian besar responden dalam penelitian ini patuh terhadap pengobatan yaitu sebanyak 20 orang $(90.91 \%)$, dan sebagian kecil tidak patuh sebanyak 2 orang $(9.09 \%)$.

\section{PEMBAHASAN}

Penelitian ini bertujuan untuk mengetahui gambaran tingkat kepatuhan pasien TB paru dalam pangobatan TB paru di Puskesmas Kota Atambua. Berikut ini adalah pembahasan tingkat karakteristik menurut Jenis Kelamin yaitu dari 22 responden yang diteliti diketahui bahwa setengah dari responden adalah berjenis kelamin laki-laki yaitu 11 orang $(50.0 \%)$ dan setengahnya berjenis kelamin perempuan yaitu sebesar 11 orang $(50.0 \%)$. Proporsi responden laki-laki dan perempuan didapatkan seimbang. Hal ini sama di kemukakan oleh Aditama, 2004 dalam Hayati, 2011 bahwa Negara berkembang, diperkirakan jumlah penderita laki-laki dan perempuan sama banyak, kendati data belum memadai. Karakteristik menurut golongan umur yaitu dari 22 responden yang diteliti adalah berumur 15-24 Tahun sebanyak 5 orang (22,7\%), umur 25-34 Tahun sebanyak 3 orang $(13,6 \%)$, umur 35-44 Tahun sebanyak 4 orang (18.2\%), umur 45-54 Tahun sebanyak 2 orang $(9,1 \%)$, umur $\geq 55$ tahun sebanyak 8 orang $(36,4 \%)$.
Tingkat pendidikan yaitu tidak sekolah sebanyak 4 orang $(18,2 \%)$, SD dengan jumlah sebanyak 3 orang (13,6\%), SMP dengan Jumlah sebanyak 3 orang $(13,6 \%)$ dan yang SMA sebanyak 10 orang $(45,5 \%)$. Sedangkan yang berpendidikan diploma/Sarjana adalah sebanyak 2 orang $(9,1 \%)$. Untuk pekerjaan adalah kelompok lain-lain sebanyak 7 orang $(31,8 \%)$ IRT sebanyak 6 orang $(27,3 \%)$, wirausaha / pedagang sebanyak 3 orang $(13,6 \%)$, pelajar / mahasiswa $(13,6 \%)$, pegawai sebanyak 2 orang $(9,1 \%)$, tidak bekerja sebanyak 1 orang (4,5\%). Adapun kelompok lain-lain yang di maksud adalah Pensiunan PNS, Pensiunan TNI, Petani, Buruh, dan pekerjaan lain yang tidak tentu. Tuberculosis biasanya menyerang orangorang yang sulit di jangkau seperti tunawisma, pengangguran dan fakirmiskin (WHO, 2003). Hal tersebut terbukti pada hasil penelitian ini, bahwa sebagian besar responden mempunyai pendapatan keluarga perbulan 1 juta s.d kurang dari 2 juta yaitu sebanyak 12 orang (54.5\%), dan sebagian kecil responden mempunyai pendapatan keluarga 2 juta s.d kurang dari 4 juta sebanyak 4 orang $(18.2 \%)$.hal ini menggambarkan bahwa keadaan ekonomi pasien TB paru masih sangat rendah. Dan dari lama berobat seluruh pasien dalam penelitian ini yaitu sebanyak 22 orang (100\%) membutuhkan waktu selama 6 bulan untuk berobat. Sedangkan Berdasarkan hasil analisis univariat didapatkan bahwa dari 22 responden di Puskesmas Kota Atambua, yang patuh terhadap pengobatan TB paru lebih besar dibandingkan dengan responden yang tidak patuh. Responden yang patuh sebanyak 20 responden $(90.91 \%)$ sedangkan responden yang tidak patuh sebanyak 2 responden $(9.09 \%)$.

Hasil penelitian ini sesuai dengan peneliti sebelumnya yang dilakukan oleh Hayati (2011) tentang Evaluasi Kepatuhan 
Berobat Penderita Tuberkulosis Paru Tahun 2010-2011 Di Puskesmas Kecamatan Pancoran Mas Depok yaitu dari 76 total responden ditemukan bahwa jumlah responden yang patuh terhadap pengobatan lebih besar dibandingkan dengan responden yang tidak patuh. Responden yang patuh berjumlah 43 responden $(56,58 \%)$ sedangkan responden yang tidak patuh berjumlah 33 responden $(43,42 \%)$. Selain itu, berdasarkan hasil penelitian yang dilakukan oleh Kirana, Lutfiyati, Wahyu (2015) tentang Gambaran Tingkat Kepatuhan Pasien Tuberkulosis Di BKPM Magelang Periode Februari - Maret 2015 yaitu berdasarkan hasil analisis dari 35 total responden, diketahui bahwa terdapat 22 responden (63\%) yang patuh, dan 13 responden (37\%) yang tidak patuh dalam menjalankan pengobatan tuberculosis paru pada bulan FebruariMaret 2015 di BKPM Magelang.

Hal ini sesuai dengan teori yang diskemukakan oleh Bart, 2004 dalam Puspitasari (2016) bahwa kepatuhan sebagai tingkat seseorang dalam melaksanakan suatu aturan dan perilaku yang disarankan, atau dengan kata lain menuruti suatu perintah atau suatu aturan. Kepatuhan adalah tingkat seseorang dalam melaksanakan perawatan, pengobatan dan perilaku yang disarankan oleh perawat, dokter atau tenaga kesehatan lainnya. Kepatuhan (coplience atau adherence) menggambarkan sejauh mana pasien berperilaku untuk melaksanakan aturan dalam pengobatan dan perilaku yang disarankan oleh tenaga kesehatan. dan Heri P, (1999) dalam buku Pengantar Perilaku Manusia mengatakan bahwa kepatuhan merupakan suatu bentuk perilaku. Perilaku manusia berasal dari dorongan yang ada didalam diri manusia, sedangkan dorongan merupakan usaha untuk memenuhi kebutuhan yang ada dalam diri manusia. Kesibukan juga menjadi alasan ketidakpatuhan, oleh karena itu OAT dianjurkan di minum pada pagi hari sebelum makan. Hal ini tidak hanya baik bagi penyerapan obat kedalam tubuh, tetapi juga agar penderita tidak lupa dalam meminum obatnya. (Aditama, 2004 dalam Hayati, 2011).

Berdasarkan fakta dan teori di atas dapat dijelaskan bahwa tingkat kepatuhan responden di Puskesmas Kota Atambua didapatkan jumlah responden yang patuh lebih besar dibandingkan dengan jumlah responden yang tidak patuh. Hal ini kemungkinan disebabkan oleh beberapa hal sebagaimana seperti yang diungkapkan oleh responden yang patuh yakni adanya keyakinan untuk sembuh dengan berobat secara teratur dan dukungan keluarga.

Berdasarkan hasil penelitian didapatkan juga ketidakpatuhan penderita TB paru dalam pengobatannya kemungkinan disebabkan oleh beberapa hal, yaitu penderita yang tidak tepat waktu minum obat/ waktu untuk minum obat selalu berubah-ubah sebanyak 1 responden ( 4.54\%), alasannya adalah karena kesibukan. Selain itu, Penderita telat untuk mengambil obat dari waktu yang telah ditetapkan sebanyak 1 responden (4.54\%), alasannya adalah karena kondisi fisiknya lemah dan keluarga sibuk sehingga lupa untuk mengambil obat.

Dengan demikian perlu dipertimbangkan oleh manajemen puskesmas (pengelola TB Paru) untuk memfasilitasi pasien TB Paru dengan pendekatan PMO terutama pada klien yang belum patuh karena PMO merupakan salah satu komponen DOTS (Direcly Observed Treatment Shortcurse) yang artinya pengobatan panduan OAT jangka pendek dengan pengawasan langsung, dimana tugas seorang PMO adalah mengawasi pasien TB agar menelan obat secara teratur sampai selesai pengobatan, memberi dorongan kepada pasien agar mau berobat 
teratur, mengingatkan pasien untuk periksa ulang dahak pada waktu yang telah ditentukan, memberi penyuluhan pada anggota keluarga pasien TB yang mempunyai gejala-gejala mencurigakan TB untuk segera memeriksakan diri ke Fasilitas Pelayanan Kesehatan. Penelitian ini memiliki beberapa keterbatasan diantaranya adalah penelitian ini menggunakan kuesioner (pertanyaan tertutup) sehingga responden hanya sebatas memilih jawaban yang tersedia, hal ini menyebabkan peneliti belum bisa mendapatkan data secara mendalam tentang (faktor - faktor yang mempengaruhi) tingkat kepatuhan pasien dalam pengobatan TB paru di Puskesmas Kota Atambua. Selain itu peneliti tidak mengikuti pasien dari awal terapi sampai dengan akhir terapi tetapi hanya mendapatkan informasi dari pasien tentang pengobatannya.

\section{KESIMPULAN}

Terdapat 20 responden $(90.91 \%)$ yang patuh dan 2 responden $(9.09 \%)$ yang tidak patuh dalam menjalankan pengobatan TB paru pada tahun 2018 di Puskesmas Kota Atambua. Disarankan kepada pengelola program TB Paru di Puskesmas kota Atambua agar tetap mengevaulasi minum obat pasien secara teratur. Untuk peneliti selanjutnya agar melakukan penelitian serupa dengan menganalisa faktor-faktor yang mempengaruhi kepatuhan minum obat TB Paru.

\section{KEPUSTAKAAN}

Brunner \& Suddarht (2014) Keperawatan Medikal Bedah. Jakarta: EGC

Hayati, A. (2011) Evaluasi Kepatuhan berobat penderita tuberkulosis paru tahun 2010-2011 di puskesmas Kecamatan pancoran Mas Depok. Diakses tanggal 12 September 2018 pukul 13.00. http://lib.ui.ac.id/file?file=digital/ 20205393-S121-

Evaluasi\%20kepatuhan.pdf

Kemenkes RI. (2011) Pedoman Nasional pengedalian Tuberkulosis. Jakarta: Kemenkes RI Dirjen Pengendalin Penyakit dn Penyehtan Lingkungan

KEMENKES RI. (2017). Data dan Informasi Profil Kesehatan Indonesia thaun 2016. Dikses tnggl12 September 2018 jam. 13.00 .

http://www.depkes.go.id/resource s/download/pusdatin/profilkesehatan-indonesia/ProfilKesehatan-Indonesia-2016.pdf.

Mete, K.K. (2015). Profil Kesehatan Propinsi Nusa Tenggara Timur. Kupang: Dinkes Propinsi NTT

Muttaqin,A. 2012. Asuhan Kepperawatan Klien Dengan Gangguan Sistem Pernapasan. Jakarta. Salemba Medika

Nurarif, A.H.Kusuma. 2016. Aplikasi Asuhan Keperawatan Berdasarkan Diagnosa Medis Nanda Nic Noc Edisi Revisi Jilid 3. Jogjakarta. mediAction.

Pameswari, A Halim, L Yustika. (2016). Tingkat Kepatuhan Penggunaan Obat pada Pasien Tuberkulosis di Rumah Sakit Mayjen H. A Thalib Kabupaten Kerinci. Jurnal sains farmasi \& klinis, - jsfkonline.org

Kirana,R.C, Lutfiyati,H., I Wahyu. (2016). Gambaran Tingkat Kepatuhan Pasien Tuberkulosis Di Bkpm 
Magelang Periode Februari -

Maret 2015. Jurnal Farmasi Sains

Dan Praktis, Vol.I, No.2

Safii, S., Putri, S. T., \& Suparto, T. A. (2018). Gambaran Kepatuhan Pasien Tuberkulosis Paru Terhadap Regimen Terapeutik Di Puskesmas Padasuka. Jurnal Pendidikan Keperawatan Indonesia,

Widoyono. (2005) Penyakit Tropis epidemiologi penularan penceghan dan pemberantasannya. Jakarta: Erlangga 